\title{
Lean production tools and decision latitude enable conditions for innovative learning in organizations: a multilevel analysis
}

\author{
Anna-Carin Fagerlind Ståhl, Maria Gustavsson, Nadine Karlsson, Gun Johansson and Kerstin \\ Ekberg
}

\section{Linköping University Post Print}

\section{Tweet}

N.B.: When citing this work, cite the original article.

Original Publication:

Anna-Carin Fagerlind Ståhl, Maria Gustavsson, Nadine Karlsson, Gun Johansson and Kerstin Ekberg, Lean production tools and decision latitude enable conditions for innovative learning in organizations: a multilevel analysis, 2014, Applied Ergonomics, (47), 285-291.

http://dx.doi.org/10.1016/j.apergo.2014.10.013

Copyright: Elsevier http://www.elsevier.com/

Postprint available at: Linköping University Electronic Press http://urn.kb.se/resolve?urn=urn:nbn:se:liu:diva-112552 
Lean production tools and decision latitude enable conditions for innovative learning in organizations: a multilevel analysis 
Abstract

The effect of lean production on conditions for learning is debated. This study aimed to investigate how tools inspired by lean production (standardization, resource reduction, visual monitoring, housekeeping, value flow analysis) were associated with an innovative learning climate and with collective dispersion of ideas in organizations, and whether decision latitude contributed to these associations. A questionnaire was sent out to employees in public, private, production and service organizations $(n=4442)$. Multilevel linear regression analyses were used. Use of lean tools and decision latitude were positively associated with an innovative learning climate and collective dispersion of ideas. A low degree of decision latitude was a modifier in the association to collective dispersion of ideas. Lean tools enable shared understanding and collective spreading of ideas, needed for the development of work processes, especially when decision latitude is low. Value flow analysis played a pivotal role in the associations.

Keywords: psychosocial work conditions; job resources; learning climate

Highlights

- Innovative learning climate and sharing ideas is necessary for innovative learning

- The use of lean tools can facilitate questioning, new thinking, and sharing ideas

- Also decision latitude can enable a climate for innovative learning

- Lean tools enable sharing of ideas especially when decision latitude is low

- Especially value flow analysis can create an arena for shared understanding 


\section{Introduction}

Lean is a production system that claims to create learning organizations through continuous improvements (Liker \& Meier, 2006). Aspects of lean production are common in all sectors, in Sweden (Johansson \& Abrahamsson, 2009) as well as in other European countries (Arundel et al., 2007; Radnor et al., 2012). However, there is an ongoing debate concerning its effect on learning, possibly due to the many different ways of interpreting and operationalizing lean production (Pettersen, 2009; Westgaard \& Winkel, 2010); Hasle, 2011; Brännmark, Langstrand, Johansson, Halvarsson, Abrahamsson \& Winkel, 2012; Hasle, Bojesen, Langaa Jensen \& Bramming, 2012). As lean production can be defined in many ways (Pettersen, 2009), its effect on learning might depend on what is implemented - for instance, if tools such as standardization and visual monitoring can be considered aids for time-consuming routine tasks, or if they are to be seen as means of control. Depending on how new working methods are implemented, organizational changes aimed at reducing variation and waste, such as lean production, may affect employee experience of the work environment and conditions for learning (Adler \& Borys 1996). Changes and formalization of the work process can be coercive, characterized by forced compliance, introduction of rules, and focus on technical and financial methods; or they can be enabling, encouraging employee involvement in problem solving, and stressing learning and innovation (Adler \& Borys 1996; Eklund, 2000).

Lean production operates by reducing unnecessary variation and steps in the work process, and consists of a set of operational tools and a strategic or philosophical part (Shah \& Ward, 2001). The philosophical level concerns how to understand value (what is needed and wanted by the customer or client) and how the work process can be improved by removing steps without value (Womack \& Jones, 1996; Womack, Jones \& Roos, 2007). Lean production tools are often implemented in order to eliminate non-value-adding activities and 
reduce variability in the work process, without considering the lean production philosophy (Shah \& Ward, 2001; Radnor, Holweg \& Waring, 2012; Joosten, Bongers, \& Janssen, 2009; Mazzocato, Savage, Brommels, Aronsson \& Thor, 2010). It is often argued that failure to consider the holistic, process view of lean production and the socio-technical aspects of the interaction between human behaviour and operational tools leads to restricted success (Liker \& Morgan, 2006; Joosten et al., 2009; Mazzocato et al., 2010; Radnor et al., 2012). If aspects of lean production is combined with socio-technical thinking, where the social as well as the technical system of the organization are considered and aspects such as work content and variation, learning, decision making, recognition and coherence are acknowledged (Thorsrud \& Emery, 1969), this may have beneficial effects on the work environment (Seppälä \& Klemola, 2004).

Improvement strategies and just-in-time practices (i.e. producing and delivering the right items at the right time in the right amounts) are the aspects most frequently mentioned in studies on lean implementations (Womack \& Jones, 1990) (Pettersen, 2009). Tools such as value flow analysis, resource reduction, standardization, and housekeeping (5s) are also common (Pettersen, 2009; Brännmark et al., 2012). The standardization of processes aims to provide a standard on which to improve, and to facilitate involvement in problem solving and improvement by freeing up time for new thinking (Liker \& Meier, 2006). Resource reduction (i.e. reducing set-up time, lead time, inventories and buffers) aims to reveal problems in the work process and facilitate just-in-time production (Liker \& Morgan, 2006). Value flow analysis, mapping or flow-charting the operations, identifies the specific actions required to bring a specific product through the entire work process and reduce the steps that create no value (Womack \& Jones, 1996). Visual control and monitoring (e.g. posting results on displays and notice boards) provides information on how work is going and how it should be done, in order to facilitate standardization as well as communication, cooperation and 
participation within the work group (Liker \& Meier, 2006). Housekeeping, or 5S (i.e. sorting out what is wasteful, straightening up and putting in its right place, shining and keeping tidy, standardizing, and sustaining this housekeeping process), is a way of maintaining visual control, standardizing and facilitating communication and participation in the work process (Liker \& Meier, 2006; Liker \& Morgan, 2006).

\subsection{Innovative learning climate and collective dispersion of ideas}

It is possible to identify potentially positive as well as negative effects of lean production on innovative learning (Ellström, 2001). Innovative learning can occur when established definitions of problems or mutual goals are questioned, discussed and analysed (Engeström, 2001). In order to enable innovative learning it must be possible to question current work practice, test new ideas and collectively explore problems and improvements, and also to share and spread ideas, both within and between units within the organization (Crossan, Lane \& White, 1999; Ellström, 2010), and changes in production processes needs to be accompanied by a climate in which employees are encouraged to discuss problems and think new (Baer \& Frese, 2003). Participation in problem solving and development are important conditions for learning new at work. Standardized work tasks and clear feedback might enable participation, but too strict standardization and goal-setting may also stifle innovative learning (Adler \& Borys, 1996; Ellström, 2001). In organizations working with lean production, participation in decision making, employee involvement and opportunities for learning and reflection can be reduced by high performance pressure, precise standards and intensified work pace and demands (Landsbergis, 1999; Parker, 2003; Sprigg \& Jackson 2006; Lorenz \& Valeyre, 2005).

However, routinization of tasks can also free up time for learning and innovation (Ohly, Sonnentag \& Pluntke, 2006). According to the literature promoting lean production, 
time for creativity and innovation in the work process can be achieved by standardizing work tasks and making the best practice of today visible for all. Individuals' ideas and improvements on that standard can then be dispersed and benefit the entire organization (Liker \& Meier, 2006). Innovative learning has however been found less likely in lean organizations, possibly due to increased standardization, production pressure, and a reduced level of discretion in problem solving (Lewis, 2002; Arundel, Lorenz, Lundvall, \& Valeyre, 2007).

It has been suggested that Sweden, due to a strong history of socio-technical traditions (Johansson \& Abrahamsson, 2009) and an emphasis on decision latitude in work organization (Arundel et al., 2007), use a "Scandinavian" model of lean production which could involve a more participative lean organization (Säppäla \& Klemola, 2004; Brännmark \& Eklund, 2013). Decision latitude - the authority over decisions, the breadth of skill usable on the job, and opportunities to develop skills - is an important part of everyday work (Karasek \& Theorell, 1990). Decision latitude is an important condition for learning and reflection (Karasek \& Theorell, 1990; Ellström, 2001), especially when work pace and demands are intensified (van Ruysseveldt \& van Dijke, 2011), and is important for innovation and initiative (Ohly et al., 2006). A high degree of decision latitude at work is a job resource that enables employees to take advantage of an innovative learning climate at work (Fagerlind, Gustavsson, Johansson \& Ekberg, 2013).

Hypothesis 1: the use of lean production tools is positively associated with an innovative learning climate and collective dispersion of ideas in organizations.

Hypothesis 2: A high degree of decision latitude enhance the association between the use of lean tools and a) innovative learning climate and b) collective dispersion of ideas in organizations. 


\section{Method}

Twelve organizations were invited to participate in the study. Ten public and private Swedish organizations agreed to participate, and employees filled in a questionnaire during working hours. The organizations were four municipalities (one entire organization and parts of three others), parts of a county council, a private production company and a private care company, and three governmental organizations. A questionnaire was sent out to a total of 8340 employees, and $n=4904$ were returned, giving a response rate of $58 \%$. Only subordinates were included in the present analyses $(n=4442$, response rate $56 \%)$, as work conditions within the same organization can differ between managers and employees (Lundqvist, Reineholm, Gustavsson \& Ekberg, 2013). The organization and department to which each individual belonged was coded, making it possible to follow the respondents in each organization and work group, and to control for the potential bias of differences in organizations and departments. Respondents worked within 70 departments nested within the ten organizations. The majority of the respondents (64\%) were women, and $44 \%$ had a university education (Table 1). The respondents (mean age 47 years) were older than the nonresponders (mean age 46 years) $(p=.01)$ but there was no statistically significant difference between responders and non-responders $(p=0.49)$ concerning gender. The response-rate varied between the organizations, from $76 \%$ (in the Government authority) to $48 \%$ (in the County council). 
Table 1. Organizations included: number of participants, mean age (standard deviation), gender distribution, and educational level.

\begin{tabular}{|c|c|c|c|c|c|}
\hline Organization & $n$ & $\begin{array}{l}\text { Mean age } \\
\text { (SD) }\end{array}$ & $\begin{array}{l}\text { Women } \\
(\%)\end{array}$ & $\begin{array}{l}\text { University } \\
\text { education }(\%)\end{array}$ & $\begin{array}{l}\text { Secondary } \\
\text { education }(\%)\end{array}$ \\
\hline $\begin{array}{l}\text { Industrial company: } \\
\text { assemblers, engineers }\end{array}$ & 597 & $\begin{array}{l}41.42 \\
(11.43)\end{array}$ & 16.5 & 13.8 & 74.8 \\
\hline $\begin{array}{l}\text { Private care company: care } \\
\text { staff }\end{array}$ & 633 & $\begin{array}{l}46.22 \\
(11.42)\end{array}$ & 75.7 & 18.9 & 68.9 \\
\hline $\begin{array}{l}\text { Municipality 1: eldercare } \\
\text { staff, care and social }\end{array}$ & 248 & $\begin{array}{l}48.71 \\
(8.99)\end{array}$ & 74.7 & 57.5 & 36.8 \\
\hline workers & & & & & \\
\hline $\begin{array}{l}\text { Municipality } 2 \text { : high school } \\
\text { personnel }\end{array}$ & 350 & $\begin{array}{l}50.67 \\
(10.28)\end{array}$ & 64.0 & 84.6 & 12.6 \\
\hline Municipality 3: various & 809 & 48.69 & 86.9 & 39.4 & 49.0 \\
\hline occupations $^{1}$ & & $(10.54)$ & & & \\
\hline Municipality 4: & 63 & 48.98 & 60.7 & 47.6 & 46.0 \\
\hline administrative staff & & $(9.96)$ & & & \\
\hline Government authority: civil & 773 & 49.33 & 85.9 & 51.1 & 44.0 \\
\hline servants & & $(10.29)$ & & & \\
\hline Government organization & 174 & 46.78 & 16.1 & 64.4 & 35.1 \\
\hline 1: civil servants & & $(8.52)$ & & & \\
\hline Government organization & 492 & 45.70 & 35.0 & 54.1 & 43.2 \\
\hline 2: civil servants & & $(12.43)$ & & & \\
\hline
\end{tabular}




$\begin{array}{lccccc}\text { County council: hospital } & 303 & 46.87 & 88.4 & 59.7 & 34.6 \\ \text { staff } & & (11.00) & & & \\ \text { Total } & & & & \\ & 4442 & 47.08 & 64.3 & 43.8 & 48.6 \\ & & (11.16) & & & \\ p & & <.001 & <.001 & <.001 & <.001\end{array}$

${ }^{1}$ Nurses, assistant nurses, teachers, administrative staff, other

\subsection{Measures}

The use of tools inspired by lean production was measured by five items (standardized work practice, visual control, housekeeping (5S), value stream mapping, and resource reduction). A sixth alternative "do not know" was possible, and categorized as missing. Responses were given on a five-point scale, and a mean score was calculated. An index was created, internal consistency Cronbach's $\alpha=.77(n=3014)$.

Innovative learning climate was measured by six items (e.g. It is easy to obtain sufficient resources if we want to try out new ideas; We have opportunities to try out new ideas with uncertain outcome). Responses were given on a five-point scale and a mean score was calculated. The internal consistency of the scale was Cronbach's $\alpha=.86(n=4262)$.

Collective dispersion of ideas within and between units/departments in the organizations was measured by five items (e.g. At our workplace we openly discuss how we can handle the difficulties we encounter at work. How well do new solutions and improvements spread within the unit/department/ to other units/departments?). Responses were given on a five-point scale and a mean score was calculated. Internal consistency of the scale: Cronbach's $\alpha=.81(n=4241)$. 
Decision latitude and psychological demands were measured with the Swedish Demand Control Questionnaire, consisting of five items measuring psychological demands (e.g. Does your job requires you to work very hard? Do you have sufficient time for all your work tasks?) and six items measuring decision latitude (e.g. Do you have the opportunity to decide for yourself how to carry out your work? Do you have the opportunity to learn new things in your work?) (Karasek \& Theorell, 1990; Sanne, Torp, Mykletun, \& Dahl, 2005). For both scales, answers were given on a four-point scale. Internal consistency: decision latitude Cronbach's $\alpha .67(n=4355)$, psychological demands $\alpha .79(n=4304)$.

Age, education (primary, secondary, university level) and gender were considered possible confounders at the individual level.

\subsection{Analysis}

Mean differences between organizations were assessed by analysis of variance. Differences between respondents and non-respondents concerning age and gender were assessed with chisquared test and analysis of variance. Missing items in a scale were replaced according to the convention of the SF-36 questionnaire (Ware, Snow, Kosinski, \& Gandek, 1993): a total score was calculated for a person if at least half of the questions of the scale were answered. The missing items were given the average score of the other items in the scale.

The primary outcome variables, (1) innovative learning climate and (2) collective dispersion of ideas, were analysed with multilevel linear regression with random intercept and fixed variables using mixed (STATA13). A three-level random intercept regression model was used to account for the hierarchical nature of the data considering individuals at first level, departments at second level, and organizations at third level. All other explanatory levels were measured on the individual level and analysed as fixed variables. 
All models included a random intercept to account for clustering effects within department and organization (Snijders \& Bosker, 2012). The analyses were adjusted successively as follows: 1) Empty model without covariates to estimate intra-organization and intra-department correlations (ICC), 2) Model I: inclusion of lean tool index, age, gender and education, and 3) Model II: addition of decision latitude and psychological demands. In addition, the associations between separate lean tool items and an innovative learning climate/a collective dispersion of ideas were investigated using multilevel linear regressions adjusted for age, gender and educational level. In order to investigate a possible interaction between decision latitude and the use of lean tools, effect modification analysis was performed by adding the appropriate interaction term to the adjusted multilevel regression model. The interaction analysis between decision latitude and the use of lean tools was tested by using the likelihood ratio test to compare the models that excluded and included the interaction parameter.

All psychosocial scales used as predictors in the regression analysis were standardized with mean zero and standard deviation one in the study population for the purpose of comparability. All tests were performed two-sided at $p<0.05$. All data management and preliminary statistical analyses were performed using SPSS 20 (IBM Corporation, Somers NY, USA) and multilevel analyses were performed in STATA (version 13, StataCorp LP, College Station, TX, USA).

\section{Results}

Use of lean tools, innovative learning climate, collective dispersion of ideas, decision latitude and psychological demands differed between the organizations $(p<.001)$ (Table 2). Employees reported a low degree of lean tool use, with the exception of the two private companies, where the highest degree of lean tool use was displayed. In the private industrial 
company, employees reported a low degree of innovative learning climate, collective dispersion of ideas, and decision latitude. In the private care company, however, where the degree of lean tool use was high, employees also reported a low degree of decision latitude, but a high degree of innovative learning climate and collective dispersion of ideas. 
Table 2: Use of lean tools, innovative learning climate, collective dispersion of ideas, decision latitude and psychological demands in each organization: mean and standard deviation $(S D)$

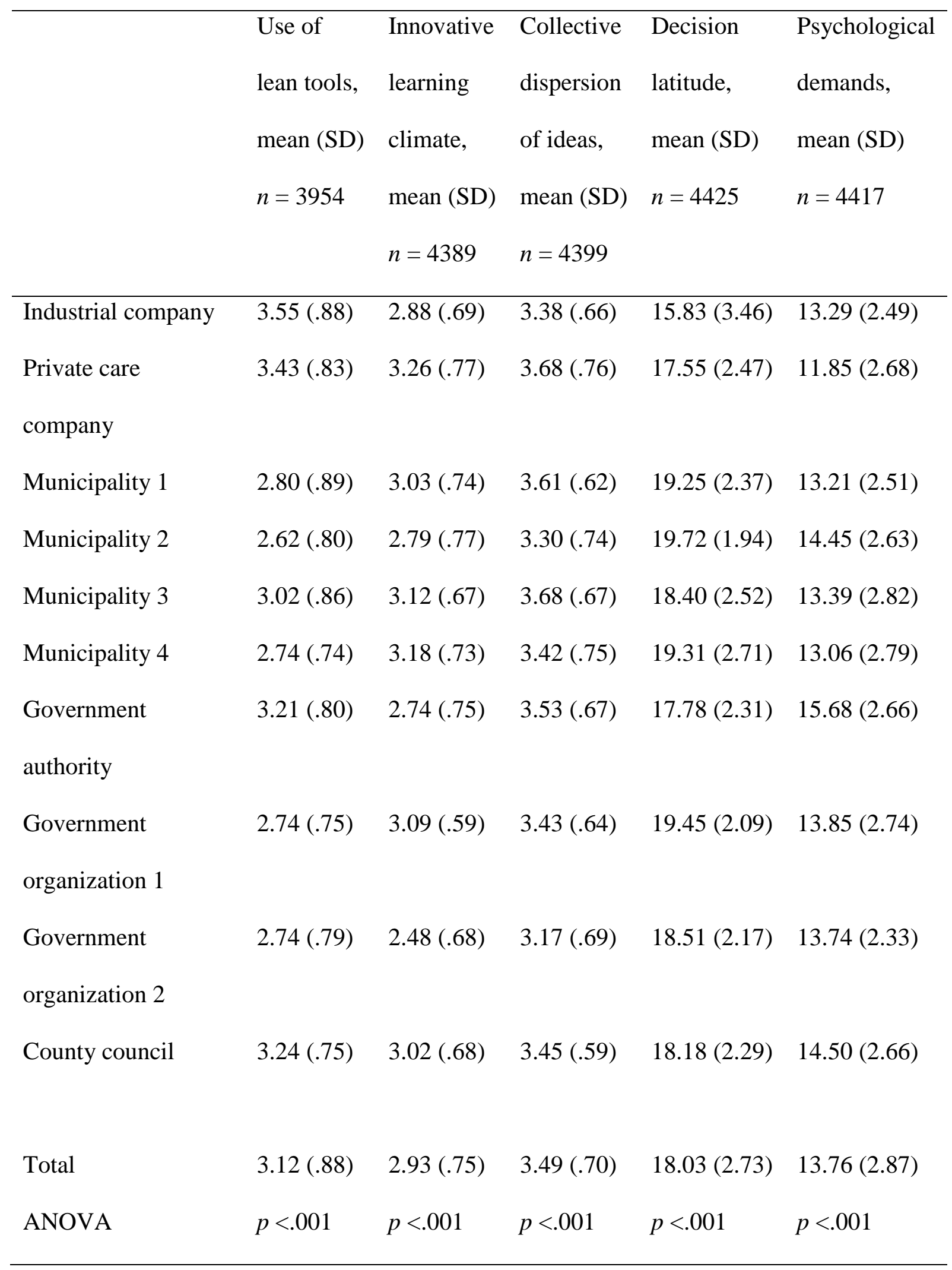


Associations between lean tool use, decision latitude, innovative learning climate and collective dispersion of ideas and are shown in Table 3. The beta-coefficients indicate the increase in one standard deviation in the outcome variable that is due to one standard deviation increase in the predictor variable. Use of lean tools was positively associated with an innovative learning climate $(\beta .23, p<.001)$ and with collective dispersion of ideas between and within units $(\beta .20, p<.001)$, adjusted for age, gender, educational level, and controlled for the random effects of organization and department (Models 1a and 1b, Table 3), and our first hypothesis was confirmed.

After the inclusion of decision latitude and additional adjustments for psychological demands (Models 2a and 2b, Table 3), there were only minor changes in the associations between lean tool use and the outcomes. Use of lean tools $(\beta .21, p<.001)$ and degree of decision latitude $(\beta .26, p<.001)$ were positively associated with an innovative learning climate. Use of lean tools $(\beta .19, p<.001)$ and degree of decision latitude $(\beta .19, p<.001)$ were also positively associated with collective dispersion of ideas.

There was a significant interaction effect $(p<.001)$ between the use of lean tools and decision latitude in relation to collective dispersion of ideas. Stratifying the analysis by the degree of decision latitude (high and low, defined by cut-off at the median), the use of lean tools was associated with a higher increase in collective dispersion of ideas $(\beta .27 ; p<.001)$ when there was a low degree of decision latitude, compared to when there was a high degree of decision latitude $(\beta .15 ; p<.001)$. There was no significant interaction effect between the use of lean tools and decision latitude in relation to innovative learning climate $(p=.873)$. Thus the second hypothesis was rejected: a high degree of decision latitude did not enhance the association between the use of lean tools and a) innovative learning climate and b) collective dispersion of ideas in organizations. 
The empty models, without confounders, showed that $7 \%$ of the variance in the innovative learning climate and $4 \%$ in the variance in the collective dispersion of ideas were related to organizational factors. $12 \%$ of the variance in the innovative learning climate, and $7 \%$ of the variance in the collective dispersion of ideas was related to department factors that is, variation is likely to depend on variables that differ between departments and organizations. 
Table 3: Multilevel linear regressions of associations between the use of tools inspired by lean production and decision latitude in relation to a) innovative learning climate and $b$ ) collective dispersion of ideas. Models $1 a$ and $b$ : univariate models; models $2 a$ and $b$ include decision latitude and are adjusted for demands. Standardized regression coefficients $(\beta)$ and their associated p-value.

\begin{tabular}{|c|c|c|c|c|c|c|c|c|}
\hline & \multicolumn{4}{|c|}{ Innovative learning climate } & \multicolumn{4}{|c|}{ Collective dispersion of ideas } \\
\hline & \multicolumn{2}{|c|}{ Model 1a } & \multicolumn{2}{|c|}{ Model 2a } & \multicolumn{2}{|c|}{ Model 1b } & \multicolumn{2}{|c|}{ Model 2b } \\
\hline & $\beta$ & $p$ & $\beta$ & $p$ & $\beta$ & $p$ & $\beta$ & $p$ \\
\hline $\begin{array}{l}\text { Use of lean } \\
\text { tools }\end{array}$ & .23 & .000 & .21 & .000 & .20 & .000 & .19 & .000 \\
\hline Decision & & & .26 & .000 & & & .19 & .000 \\
\hline latitude & & & & & & & & \\
\hline Demands & & & -.19 & .000 & & & -.16 & .000 \\
\hline Age & -.00 & .841 & .00 & .228 & .00 & .777 & -.00 & .627 \\
\hline $\begin{array}{l}\text { Gender: } \\
\text { women } \\
\text { (ref) }\end{array}$ & & & & & & & & \\
\hline Men & .01 & .682 & .00 & .985 & -.01 & .641 & -.02 & .340 \\
\hline $\begin{array}{l}\text { Educational } \\
\text { level: } \\
\text { university } \\
\text { (ref) }\end{array}$ & & & & & & & & \\
\hline Secondary & .06 & .022 & .08 & .000 & .05 & .046 & .07 & .006 \\
\hline Primary & .08 & .119 & .10 & .029 & .03 & .550 & .03 & .441 \\
\hline
\end{tabular}


Associations between the specific lean tools and aspects of learning are shown in Table 4 (adjusted for age, gender and education). The use of value flow analysis was associated with a larger increase in both the innovative learning climate $(\beta .28, p<.001)$ and collective dispersion of ideas $(\beta .23, p<.001)$. There was a very weak association between resource reduction and an innovative learning climate $(\beta .08, p<.001)$ and collective dispersion of ideas $(\beta .08, p<.001)$, which explained no more variance than the empty models do, without covariates.

Table 4. Multilevel linear regressions of the associations between lean tool items and both an innovative learning climate and a collective dispersion of ideas. Adjusted for age, gender and education. All associations are significant at $p<.001$.

\begin{tabular}{lll}
\hline & $\begin{array}{l}\text { Innovative learning } \\
\text { climate }\end{array}$ & $\begin{array}{l}\text { Collective dispersion } \\
\text { of ideas }\end{array}$ \\
& $\beta$ & $\beta$ \\
\hline Resource reduction & .08 & .08 \\
Value flow analysis & .28 & .23 \\
Standardized work & .12 & .11 \\
Housekeeping (5S) & .16 & .17 \\
Visual control & .16 & .12 \\
\hline
\end{tabular}

\section{Discussion}

Lean production is being implemented in all sectors of working life, although little is known about associations with conditions for learning at the workplace. In this study we investigated 
how the use of tools inspired by lean production was associated with an innovative learning climate and a collective dispersion of ideas in ten Swedish organizations, and whether decision latitude affected these associations.

Employees in all ten organizations reported using tools inspired by lean production to some degree, confirming a widespread use of these working methods, in private and public organizations, as well as production and service organizations. Use of lean tools was found to be positively associated with an innovative learning climate and a collective dispersion of ideas within and between units. Working with these tools facilitated a climate where there were opportunities for employees to think along new lines and test new ideas, and to discuss and share ideas within their work group and between groups in the organization. Implementation of lean tools may thus facilitate the work process, remove unnecessary steps and tasks, and provide opportunities for employees to participate in problem solving.

Decision latitude, i.e. having opportunities to decide over how to carry out one's work, learn new skills and use the skills one has, was also found to be important for the experience of an innovative learning climate and collective dispersion of ideas. Compared with the use of lean tools, an increase in degree of decision latitude was associated with a larger increase in the degree of an innovative learning climate. It has previously been found that decision latitude is important if employees are to benefit from an innovative learning climate (Fagerlind et al., 2013).

The associations between the use of lean tools and innovative learning climate and collective dispersion of ideas were not accounted for by decision latitude: the associations changed only marginally when decision latitude was included in the analysis. However, there was a significant interaction effect between the use of lean tools and decision latitude in relation to collective dispersion of ideas. The use of lean tools was associated with more 
sharing and dispersion of ideas within and between units in the organization when the degree of decision latitude was low, compared to when the degree of decision latitude was high. When decision latitude is low, the use of lean tools could provide structure and opportunities for discussing and sharing ideas. Standardized work, focus on reduction of "non-value-adding activities" and time pressure has previously been found to reduce employee decision latitude (Landsbergis, 1999; Jackson \& Mullarkey, 2000; Parker, 2003; Hasle, 2011; Stewart et al 2013). The use of lean production tools in situation when the degree of decision latitude is high and there are opportunities to decide over one's work and use the breadth of one's skill, could be interpreted as constraining organizational change (Adler \& Borys, 1996). When the degree of decision latitude is low however, the use of lean tools could increase the opportunities for employees to participate and in engage discussion and sharing ideas, and the use of lean tools could be experienced as an enabling organizational change (Adler \& Borys, 1996). A possible selection should also be considered: the degree of decision latitude is relatively low in the organizations that use lean tools to a high degree, and it is possible that this higher degree of lean tool use explains the increased effect on collective dispersion of ideas. There was no interaction effect found in relation to innovative learning climate.

The present results contradict the suggestions that innovative learning is less likely in lean organizations (Lewis, 2002; Arundel et al., 2007) and show that the use of lean tools can enable an innovative learning climate and collective dispersion of ideas and create an arena for innovative learning in organizations. However, also decision latitude is of importance, and was associated with a higher increase in innovative learning climate than the use of lean tools, however no interaction between a high degree of decision latitude and the use of lean tools was found. Based on the organizations included, "Swedish lean" (Brännmark \& Eklund, 2013) does not appear to be characterized by a simultaneously high degree of decision latitude. Decision latitude and use of lean tools could be considered to concern different 
aspects of the work environment. Decision latitude concerns the individual's experience of authority over his/her own decisions and opportunities for using individual skills, whereas use of lean production tools seems to require teamwork and collective learning to make the production process visible in the organization. Sharing and spreading ideas is not an individual activity (Crossan et al, 1999). Use of lean production tools may provide opportunities for participation, use of skills and autonomy over decisions at this collective level, which are not captured by decision latitude. For instance, of the tools included in the lean index, the use of value flow analysis was associated with the largest increase in the reported degree of an innovative learning climate and a collective dispersion of ideas. Value flow analysis is a tool where employees map or flow-chart the operations, analyse the value flow and identify actions needed in order to make work flow smoothly. This makes the work process explicit, and the roles and actions of individuals can be understood in a larger organizational context. These are important aspects of an innovative learning climate and collective dispersion of ideas, which facilitate questioning, new thinking, and collective analysis and discussion (Engeström, 2001; Ellström, 2001).

An increase in the use of the other lean tools investigated, and especially resource reduction, was associated with a much smaller increase in both the reported innovative learning climate and the collective dispersion of ideas. Resource reduction explains no variance in the outcome compared with the empty model. Reduction of excess time, inventories and buffers is considered to reveal problems in the work process and facilitate improvements (Liker \& Morgan, 2006); however, it appears to have a minimal positive effect on the innovative learning climate and collective dispersion of ideas. Lean production can be considered a rationalization concept, removing unnecessary actions and material (Westgaard \& Winkel, 2010), and resource reduction is commonly applied (Pettersen, 2009). In the two private companies, where employees reported a high degree of lean tool use, there was a 
difference in the reported innovative learning climate and collective dispersion of ideas. Employees in the care company used value flow analysis to a high degree and reported a high degree of an innovative learning climate and collective dispersion of ideas, whereas employees in the industrial company reported a lower use of value flow analysis than other tools, and a low degree of an innovative learning climate and collective dispersion of ideas. While the use of value flow analysis could be considered an example of an enabling formalization (Adler \& Borys, 1996), that encourages employee participation and involvement in problem solving, and stresses learning and innovation, tools such as resource reduction and standardization of the work process could be used as more coercive tools to control the work process.

Although value flow analysis was associated with the largest increase in innovative climate and collective dispersion of ideas, the association between all tools investigated and the outcome was positive and significant. Standardization of the work process could provide an overall known standard and a foundation for improvements, and reduce unnecessary tasks that might otherwise cause strain and hinder involvement in problem solving (Liker \& Morgan, 2006). Visual monitoring and housekeeping could facilitate communication, cooperation and participation within the work group (Liker \& Meier, 2006). However, in previous research, lean production tools such as standardization and especially resource reduction have been found to intensify demands and reduce the degree of decision latitude (Landsbergis, 1999; Jackson \& Mullarkey, 2000; Parker, 2003; Hasle, 2011; Stewart et al 2013). Here, resource reduction concerns reduction of set-up time, lead time, inventories and buffers, and is to be distinguished from reduction of overall resources. 


\subsection{Strengths and limitations}

Despite claims that lean production facilitates learning and continuous improvements (Liker \& Meier, 2006; Liker \& Morgan, 2006), few studies have been conducted, and little is still known, of how lean production affects learning and the work environment (Hasle, 2011; Hasle et al., 2012). This study shows that there is an association between the use of tools inspired by lean production and a climate that enables innovative learning and dispersion of ideas in organizations. The study was based on data comprising employees in 70 departments within ten organizations, likely to be representative of a variety of sectors and occupations. The design of the study made it possible to match subordinates, their departments and organizations, allowing control for the random effects of departments and organizations. The multilevel approach made it possible to distinguish the relative importance of individual, department and organization in subordinates' perception of an innovative learning climate and a collective dispersion of ideas. The intra-class correlations, indicating the degree of variance in the outcomes explained by organizational or departmental level, showed that explanations for innovative learning climate (ICC 12\% for department and 7\% for organization) and collective dispersion of ideas (ICC 7\% for department and 4\% for organization) were mostly found at the individual level. However, these contextual variances were significant $(\mathrm{p}<.05)$, which indicates that conditions associated with an innovative learning climate and a collective dispersion of ideas need to be handled also at the organizational level.

Missing values for the lean tool index differ between organizations, and between the specific tools of the index in the overall sample. Although the lowest per cent of missing values on the index is found in the production company (8\%) that also report the highest use of lean tools, there is no pattern indicating that missing values vary according to the degree of lean tool use. There are more missing values on the index in organizations that use lean tools 
to a lower degree such as municipality $2(17 \%)$ and government organization $2(17 \%)$, however the highest per cent is found in municipality $3(19 \%)$ where the use of lean tools can be considered comparably average in the present sample.

Concerning the different tools, missing values ranged between $23 \%$ for resource reduction and $10 \%$ for housekeeping/5S. For value flow analysis, the missing value was $18 \%$. Resource reduction and value flow analysis were the items with most missing values in all organizations. Besides housekeeping, visual control (13\%) and standardization of work $(16 \%)$ had the lowest percentage of missing values in the overall sample, and in all organizations. The missing values were similar in all organizations, and did in all likelihood not bias the results.

The Cronbach's alpha for the decision latitude scale is somewhat low, although a value of .67 can still be considered acceptable (Dukes, 2005). The lower alpha is possibly due to the heterogeneity of the organizations and occupations included, causing employees to respond less systematically to the decision latitude scale.

Self-report method risks self-report bias and common method variance that could cause an overestimation of associations. A possible amelioration to common method variance is that the variables were part of a larger questionnaire with no clear connection between dependent and independent variables, the indexes did not follow directly on each other, and scale points and anchor labels differed between variables, which could reduce common retrieval cues (Podsakoff, MacKenzie, \& Podsakoff, 2012). Concerning the nature of the variables, there are also positive aspects of self-report method. Self-report provides information concerning how employees actually experience principles for work and opportunities for innovative learning. The perception of decision latitude, innovative learning climate and collective dispersion of ideas are subjective, and difficult to measure with other 
methods. The definition of an organization as "lean" provides little information of what is actually applied on the shop floor: the use of lean tools may also go under the name of local production systems, and managers' perceptions of lean are likely to differ from that of employees' actual use of it (Brännmark et al., 2012). Specific measurement of lean tools facilitates comparisons with other studies, but this is lacking in previous research on lean production (Brännmark et al., 2012).

The cross-sectional design of the present study is a limitation: no conclusions concerning causality can be drawn as reversed causality concerning of the associations cannot be excluded. Innovative learning climate and collective dispersion of ideas might facilitate the use of lean production tools and explain the positive association.

\subsection{Conclusions}

The present study shows that use of lean tools is associated with an innovative learning climate and collective dispersion of ideas. A good learning climate and encouragement of dispersion of ideas is important in order to facilitate development of the work process in organizations. In this study, value flow analysis was a lean tool that played a pivotal role. Value flow analysis seems to enable employees to collectively analyse and question the work process, to come together around a shared understanding of what can be done to reduce unnecessary steps and ensure that the product flows smoothly through the work process. Also decision latitude was important for the experience of job resources such as an innovative learning climate and collective dispersion of ideas at work. The use of lean tools can be experienced as more enabling for sharing ideas when decision latitude is low compared to when high. The results of the present study have implications for the organization of work, and for enabling innovative learning and development in organizations. Both decision latitude and an innovative learning climate are job resources that also help individuals to handle 
challenges at work with sufficient skills, and facilitate well-being (Bakker \& Demerouti, 2007; Fagerlind et al., 2013). 


\section{References}

Adler , P., \& Borys, B. (1996). Two types of Bureaucracy: enabling and coercive. Administrative science quarterly, 41, 61-89.

Arundel, A., Lorenz, E., Lundvall, B-Å., \& Valeyre, A. (2007). How Europe's economies learn: a comparison of work organization and innovation mode for the EU-15. Industrial and corporate change, 16, 1175-1210. doi: 10.1093/icc/dtm035

Baer, M. \& Frese, M. (2003). Innovation is not enough: climates for initiative and psychological safety, process innovations, and firm performance. Journal of organizational behavior, 24, 45-68. doi: 10.1002/job.179

Bakker, A \& Demerouti, E. 2007. The Job Demand-Resources Model: state of the art. Journal of managerial psychology, 22, 309-328. doi: 10.1108/02683940710733115

Brännmark, M., Langstrand, J., Johansson, S., Halvarsson, A., Abrahamsson, L., \& Winkel, J. (2012). Researching lean: methodological implications of loose definitions. Quality innovation prosperity 16, 35-48. doi: 10.12776/qip.v16i2.67

Brännmark, M. \& Eklund, J. (2013). Leaninspirerade förändringar och personalens upplevelser. In Sederblad, P (Ed.), Lean i arbetslivet. Stockholm: Liber.

Crossan, M., Lane, H., \& White, R. (1999). An organizational learning framework: from intuition to institution. The academy of management review, 24, 522-537.

Dukes, K. Cronbach's alpha. In Encyclopedia of biostatistics. Ed. Peter Armitage \& Theodore Colton ( $2^{\text {nd }}$ ed., vol 2). West Sussex, England: Wiley

Eklund, J. (2000). Development work for quality and ergonomics. Applied ergonomics, 31, 641-648. doi: 10.1016/0003-6870(95)95747-N

Ellström, P-E. (2001). Integrating learning and work: problems and prospects. Human resource development quarterly, 12, 421-435. doi: 10.1002/hrdq.1006 
Ellström, P-E. (2010). Practice-learning innovation: a learning perspective. Journal of workplace learning, 22, 27-40. doi: 10.1108/13665621011012834

Engeström, Y. (2001). Expansive learning at work: toward an activity theoretical reconceptualization. Journal of education and work, 14, 133-156. doi: $10.1080 / 13639080020028747$

Fagerlind, A-C., Gustavsson, M., Johansson, G., \& Ekberg., K. (2013). Experience of workrelated flow: does high decision latitude enhance benefits gained from job resources? Journal of vocational behavior, 83, 161-170. doi: 10.1016/j.jvb.2013.03.010

Hasle, P. (2011). Lean production - an evaluation of the possibilities for an employee supportive lean practice. Human factors and ergonomics in manufacturing and service industries. 24, 40-53. doi: 10.1002/hfm.20350

Hasle, P ., Bojesen, A., Langaa Jensen, P., \& Bramming, P. (2012). Lean and the working environment: a review of the literature. International journal of operation and production management. 33, 829-849. doi: 10.1108/01443571211250103

Jackson, P. \& Mullarkey, S. (2000). Lean production teams and health in garment manufacture. Journal of occupational health psychology, 5, 231-245.

Johansson, J. \& Abrahamsson, L. (2009). The good work - a Swedish trade union vision in the shadow of lean production. Applied ergonomics, 40, 775-780. doi: 10.1016/j.apergo.2008.08.001

Joosten, T., Bongers, I., \& Janssen, R. (2009). Application of lean thinking to health care: issues and observations. International journal for quality in health care, 21, 341-347. doi: 10.1093/intqhe/mzp036

Karasek, R. \& Theorell, T. (1990). Healthy work, stress, productivity, and the reconstruction of working life. ( $1^{\text {st }}$ ed.). USA: Basic books 
Landsbergis, P., Cahill, J., \& Schnall, P. (1999). The impact of lean production and related new systems of work organization on worker health. Journal of occupational health psychology, 4, 108-130.

Lewis, M. (2000). Lean production and sustainable competitive advantage. International journal of operations and production management, 20, 959-978.

Liker, J., \& Meier, D. (2006). The Toyota way field book: a practical guide for implementing Toyota's 4Ps. New York: McGraw-Hill

Liker, J., \& Morgan, J. (2006). The Toyota way in services: the case of lean production development. Academy of management perspectives, 20, 5-20.

Lorenz, E., \& Valeyre, A. (2005). Organizational innovation, human resource management and labour market structure: a comparison of the EU-15. Journal of industrial relations. 47, 424-442. doi:10.1111/j.1472-9296.2005.00183.x

Lundqvist, D., Reineholm, C., Gustavsson, M., \& Ekberg, K. (2013). Investigating work conditions and burnout at three hierarchical levels. Journal of occupational and environmental medicine, 55, 1157-1163. doi: 10.1097/JOM.0b013e31829b27df

Mazzocato, P., Savage, C., Brommels. M., Aronsson, H., \& Thor, J. (2010). Lean thinking in healthcare: a realist review of the literature. Quality and safety in health care. 19, 376382. doi: $10.1136 /$ qshc. 2009.037986

Ohly, S., Sonnentag, S., \& Pluntke, F. (2006). Routinization, work characteristics and their relationships with creative and proactive behaviors. Journal of organizational behavior, 27, 257-279. doi: 10.1002/job.376

Parker, S. (2003). Longitudinal effects of lean production on employee outcomes and the mediating role of work characteristics. Journal of applied psychology, 88, 620-634. doi: 10.1037/0021-9010.88.4.620 
Pettersen, J. (2009). Defining lean production: some conceptual and practical issues. The TQM journal, 21, 127-142. doi: 10.1108/17542730910938137

Podsakoff, P., MacKenzie, S., \& Podsakoff, N. (2012). Sources of method bias in social science research and recommendations on how to control it. Annual review of psychology, 63, 539-569. doi: 10.1146/annurev-psych-120710-100452

Radnor, Z., Holweg, M., \& Waring, J. (2012). Lean in healthcare. The unfulfilled promise? Social science and medicine, 74, 364-371. doi: 10.1016/j.socscimed.2011.02.011

Seppälä, P., \& Klemola, S. (2004). How do employees perceive their organization and job when companies adopt principles of lean production? Human factors and ergonomics in manufacturing and service industries, 14, 157-180. doi: 10.1002/hfm.10059

Shah, R., \& Ward, P. (2007). Defining and developing measures of lean production. Journal of operations management. 25, 785-805. doi: 10.1016/j.jom.2007.01.019

Snijders, T., \& Bosker, R. (2012). Multilevel analysis. An introduction to basic and advanced multilevel modeling (2nd ed). London: SAGE

Sprigg, C. \& Jackson, P. (2006). Call centers as lean service environments: job-related strain and the mediating role of work design. Journal of occupational health psychology, 11, 197-212. doi: 10.1037/1076-8998.11.2.197

Stewart, P., Danford, A., Richardson, M., \& Pugliano, V. (2010). Workers' experiences of skill, training and participation in lean and high performance workplaces in Britain and Italy. Employee relations, 32, 606-624. doi: 10.1108/01425451011083654

Van Ruysseveldt, J., \& van Dijke, M. (2011). When are workload and workplace learning opportunities related in a curvilinear manner? The moderating role of autonomy. Journal of vocational behavior, 79, 470-483. doi: 10.1016/j.jvb.2011.03.003

Ware, J., Snow, K., Kosinski, M, \& Gandek, B. (1993). SF.36 health survey. Manual and interpretation guide. Boston: The health institute, New England Medical Centre 
Waring, J., \& Bishop, S. (2010). Lean healthcare: rhetoric, ritual and resistance. Social science and medicine, 71, 1332-1340. doi: 10.1016/j.socscimed.2010.06.028

Westgaard, R.H., Winkel, J. (2011). Occupational musculoskeletal and mental health: significance of rationalization and opportunities to create sustainable product systems a systematic review. Applied ergonomics, 42, 261-296. doi:

10.1016/j.apergo.2010.07.002

Womack, P. \& Jones, D. (1996). The machine that changed the world. How to banish waste and create wealth in your corporation. New York: Simon \& Schuster. 